\title{
EOP's: Rol de la administración de corticoides en el tratamiento de la meningitis bacteriana en niños
}

\section{Escenario Clínico:}

Durante un ateneo sobre meningitis en chicos (6 meses), la residente que lo estaba presentando recomienda la utilización de dexametasona en forma conjunta con la terapia antibiótica.Se pone en cuestionamiento esta recomendación y no se logra llegar a una conclusión.

\section{Pregunta que generó el caso}

En los niños que presentan meningitis bacteriana aguda (población), ¿agregar dexametasona al tratamiento antibiótico (intervención) disminuye el riesgo de secuelas neurológicas (resultado)?

\section{Meningitis bacteriana aguda}

A pesar de los avances en el diagnóstico y manejo, las infecciones bacterianas del sistema nervioso central (SNC) generan importante morbimortalidad1. Estudios acerca de la patogénesis de la injuria del tejido nervioso han mostrado que factores inflamatorios y tóxicos producidos por la respuesta inmunológica del huésped son responsables de gran parte del daño2-3. Esta respuesta del huésped se acentúa en el momento en que se administran los antibióticos, los microorganismos son lisados y existe una liberación masiva de las paredes de las células inflamatorias.

Los corticoides producen una serie de efectos en la respuesta del huésped por lo que su uso ha sido considerado desde 1950. Han sido utilizados en meningitis aguda bacteriana y tuberculosa, pero su empleo ha sido motivo de controversia 4-5.. Esta controversia se relaciona con algunas preocupaciones como la potencial interferencia con la capacidad de respuesta inmune para controlar la infección, la disminución en la penetración de los antibióticos a través de la barrera hematoencefálica, la activación de la enfermedad extraneural en el caso de la tuberculosis, el enmascaramiento de signos útiles para juzgar la respuesta al tratamiento $y$ a posibles efectos adversos.

La mortalidad global de la meningitis bacteriana es de un $20 \%$. Además, puede generar importantes secuelas neurológicas como pérdida de audición, hidrocefalia, accidente cerebrovascular entre otras. La morbilidad puede llegar al $40-60 \%$ en los sobrevivientes. En la población pediátrica, el Haemophilus influenzae era el germen más frecuente causando el $70 \%$ de las infecciones en menores de 5 años. La introducción de la vacuna modificó este patrón en los Estados Unidos disminuyendo los casos de meningitis en un $55 \%$ y los causados por el haemophilus en un $94 \%$.

El neumococo da cuenta del $47 \%$ de los casos de meningitis y es el agente más común en mayores de 18 años y en niños entre 1 y 2 años. El meningococo es el segundo germen en frecuencia y da cuenta del $25 \%$ de todos los casos. Es el germen más común en los niños entre 2 y 18 años.

Una complicación para el tratamiento ha surgido en los últimos años con la aparición de cepas resistentes de neumococo.Un $25 \%$ es resistente a la penicilina y un $9 \%$ a las cefalosporinas de tercera gener ación.

\section{Estrategia de búsqueda}

A través de TRIPDATABASE (www.tripdatabase.com) empelando como palabra clave "meningitis" y "dexamethasone" tanto en título como en texto se recuperaron dos citas. Una era el comentario en DARE (Database of Abstracts of Reviews of Effectiveness) de un meta-análisis del JAMA de 1997, y la otra el resumen y comentario del mismo meta análisis del Journal Club del American College of Physicians.Se leyeron ambos resúmenes y se decidió buscar el meta-análisis original.

\section{Resumen de la evidencia}

McIntyre PB, Berkey CS, King SM, et al. Dexamethasone as adjunctive therapy in bacterial meningitis: a meta-analysis of randomized clinical trials since 1988. JAMA. 1997 Sep $17 ; 278: 925-31$

\section{Objetivo}

Evaluar a través de un meta-análisis la eficacia y la seguridad de la dexametasona como terapia adyuvante en las meningitis bacterianas.

\section{Fuentes de información}

Los estudios fueron identificados a través de búsquedas en MEDLINE, HEALTHLINE, y AIDSLINE (1988 a Noviembre de 1996) usando como términos MeSH dexamethasone and meningitis, consultando la bibliografía de los trabajos relevantes y contactando a los autores de los trabajos publicados.

\section{Selección de estudios}

Se incluyeron los estudios que estuvieran aleatorizados, controlados y que emplearan dexametasona en niños con meningitis bacteriana. Se incluyeron estudios no aleatorizados sólo en la evaluación de efectos adversos.

\section{Extracción de información}

Se evaluó la dosis de antibióticos y dexametasona, el momento de la administración de dexametasona y duración del tratamiento corticoide, edad de los pacientes, germen causal, pérdida de audición y otras secuelas neurológicas y efectos adversos.

\section{Resultados principales}

Se identificaron 16 estudios de los cuales 11 cumplían los criterios de inclusión. La incidencia de pérdida en la agudeza auditiva severa difirió según el germen causal en el grupo control. Por lo tanto, se calculó la tasa de eventos específica por bacteria (ver tabla). En las meningitis causada por Haemophilus influenzae tipo b (Hib), la dexametasona redujo la pérdida severa de audición ( $P$ $=0.004)$. Resultados similares se obtuvieron al estratificar los estudios de acuerdo con el momento de administración del corti- 
coide (antes o con el antibiótico vs. luego) o por el tipo de antibiótico (cefuroxime vs. otro). En las meningitis causadas por neumococo, la pérdida severa de audición se redujo sólo en aquéllos en los cuales la dexametasona se administró tempranamente $(P=0.018)$. Otros déficit neurológicos no difirieron entre grupos. La aparición de fiebre secundaria fue el único efecto adverso que resultó más frecuente en el grupo tratado con dexametasona (39\% vs. $27 \%$, aumento de riesgo absoluto* $12 \%$, IC95\% $2 \%$ a 21\%, número necesario para dañar ${ }^{*} 9$ ).

\section{Dexametasona vs placebo}

\begin{tabular}{l|l|l|l|l|l}
\hline $\begin{array}{l}\text { Pérdida de } \\
\text { audición }\end{array}$ & $\begin{array}{l}\text { Eventos } \\
\text { ponderados en } \\
\text { grupo } \\
\text { intervención }\end{array}$ & $\begin{array}{l}\text { Eventos } \\
\text { ponderados } \\
\text { en grupo } \\
\text { control }\end{array}$ & $\begin{array}{l}\text { Reducción } \\
\text { riesgo } \\
\text { relativo } \\
\text { (IC 95\%) }\end{array}$ & $\begin{array}{l}\text { Reducción } \\
\text { riesgo } \\
\text { absoluto } \\
\text { ponderado }\end{array}$ & $\begin{array}{l}\text { NNT } \\
\text { (IC 95\%) }\end{array}$ \\
$\begin{array}{l}\text { Meningitis por } \\
\text { haemophilus }\end{array}$ & $6 \%$ & $12 \%$ & $68 \%(27-84)$ & $6 \%$ & $16(10-51)$ \\
\hline $\begin{array}{l}\text { Meningitis por } \\
\text { neumococo }\end{array}$ & $6 \%$ & $18 \%$ & $76 \%(12-93)$ & $12 \%$ & $9(5-48)$ \\
\hline
\end{tabular}

Los autores del meta-análisis comentan que desde la aceptación para publicar el trabajo hasta su aparición, encontraron un ensayo que no estaba en MEDLINE en la búsqueda original. Se trata de un estudio realizado en Pakistán con hallazgos muy frecuentes en el tercer mundo: $55 \%$ de casos con cultivo negativo, tratamiento antibiótico previo (44\%) y consulta tardía ( $42 \%$ con más de 4 días de evolución). En el grupo tratado con dexametasona se observó una mayor mortalidad (12 de 48 pacientes con tratamiento, 5 de 41 en los controles, OR 2.05 IC $95 \%$ 0.8-5.3). No se reportaron datos específicos según agente causal.

\section{Conclusión}

El tratamiento adyuvante con dexametasona reduce la pérdida severa de audición en los niños con meningitis por haemophilus influenzae tipo b. En los casos de meningitis por neumococo, este efecto se advierte si la dexametasona es administrada precozmente.

\section{Comentario}

Podríamos concluir que existe indicación para empelar dexametasona como terapia adyuvante en las meningitis por Hib en niños mayores a 6 meses. El uso de corticoides en meningitis por otras causas es más controvertido.Es probable que la controversia se relacione con la falta de poder en análisis de subgrupos de los ensayos individuales que con verdaderas diferencias biológicas. En consecuencia, debería recomendarse la administración temprana de corticoides a todos los niños con meningitis aguda.

El estudio de McIntyre aporta datos de países desarrollados. Debemos considerar que no debe administrarse dexametasona en pacientes meningitis no bacteriana, meningitis parcialmente tratada y a aquéllos con síntomas de más de 4 días de evolución. En estos casos, el empleo de corticoides puede empeorar el cuadro6. Cuando el Hib es el patógeno predominante, dos días de dexametasona son tan efectivos como cuatro, con la ventaja de reducir costos y efectos adversos como fiebre y hemorragia digestiva.

A pesar del tratamiento, algunos niños mueren o tienen secuelas como consecuencia de la meningitis bacteriana. Por lo tanto la búsqueda de tratamientos adyuvantes para disminuir la mortalidad y las consecuencias a largo plazo es una tarea que no debe abandonarse.

\section{Dr. Sebastián García Martí [ Becario de Gerenciamiento del Plan de Salud del Hiospital Italiano de Buenos Aires ]}

\section{Referencias}

1.Quagliarello VJ, Scheld WM. Treatment of bacterial meningitis. N Engl J Med. 1997;336:708-710.

2. Pfister HW, Scheld WM. Brain injury in bacterial meningitis: therapeutic implications.Curr Opin Neurol. 1997;10:254-259.

3. Tunkel AR, Scheld WM. Pathogenesis and pathophysiology of bacterial infections. In:Scheld WM, Whitley RJ, Durack DT, eds. Infections of the Central Nervous System.2nd ed.Philadelphia, Pa:Lippincott-Raven Publishers; 1997:297-312.

4. Zuger A, Lowy FD. Tuberculosis. In: Scheld WM, Whitley RJ, Durack DT, eds. Infections of the Central Nervous System.2nd ed.Philadelphia, Pa:Lippincott-Raven Publishers;1997:417-443.

5. Schaad UB, Kaplan SL, McCracken GH.Steroid therapy for bacterial meningitis.Clin Infect Dis. 1995;20:685-690.

6. Qazi SA, et al. Dexamethasone and bacterial meningitis in Pakistan. Arch Dis Child 1996; 75:482-488. 